\title{
Clinical assessment of epidural analgesia induced by xylazine-lidocaine combination accompanied by xylazine sedation in calves
}

\author{
Alkan Kamiloglu', Nadide Nabil Kamiloglu², Savas Ozturk', \\ Gultekin Atalan' and Engin Kılıc' \\ ' Department of Veterinary Surgery, \\ ${ }^{2}$ Department of Veterinary Physiology, \\ Faculty of Veterinary Medicine, University of Kafkas, Kars, 36100, Turkey.
}

\author{
Key words \\ Cattle \\ Calves, \\ Analgesia, \\ Xylazine, \\ Lidocaine.
}

\begin{abstract}
The aim of the present study was to investigate whether epidural administration of a xylazine-lidocaine combination accompanied by xylazine sedation would provide satisfactory analgesia for some surgical procedures on 10 calves admitted to the Department of Veterinary Surgery, University of Kafkas with perineal urolithiasis (n:2), rectovaginal fistula (n:I), atresia ani (n:2), omphalophlebitis (n:2), omphaloarteritis (n:I) and umbilical hernia (n:2).

Following intramuscular injection of xylazine at a dose of $0.05 \mathrm{mg} / \mathrm{kg}$ for sedation, xylazine-lidocaine combination $(0.2 \mathrm{mg} / \mathrm{kg}$ lidocaine $+0.02 \mathrm{mg} / \mathrm{kg}$ xylazine $+5 \mathrm{ml} 0.9 \% \mathrm{NaCl})$ was administrated into the lumbosacral $\left(\mathrm{L}_{6}-\mathrm{S}_{1}\right)$, sacrococcygeal $\left(\mathrm{S}_{5}-\mathrm{Co}_{1}\right)$ or intercoccygeal $\left(\mathrm{Co},-\mathrm{CO}_{2}\right)$ space. Heart rate, respiratory rate and rectal temperature were recorded prior to and during analgesia at 5, I0, I5, 30 and 60 minutes. Furthermore, depth and duration of analgesia were evaluated during surgical intervention.

The study revealed that the combination of epidural xylazine-lidocaine with xylazine sedation was highly satisfactory for surgery of the lower urinary tract and the perineal region, but it was less so for surgery of the umbilical area.
\end{abstract}

\section{Introduction}

Xylazine, one of the alpha ${ }_{2}$ agonists, has been widely used in veterinary practice both systemically as a sedative and analgesic drug (Thurman et al., 1989), and neuraxially for analgesia in various species (Caron and LeBlanc, 1989; DeRossi et al., 2003; Grubb et al., 1993; LeBlanc et al., 1988; St. Jean et al., 1990). It causes muscle relaxation and, depending on the dose used, it can induce cardiorespiratory depression, a fall in body temperature, a reduction in ruminal activity, a reduction in swallowing (hence, drooling of saliva) with an increased risk of aspiraton, and diuresis (Picavet et al., 2004; Thurman et al., 1989; Zuagg and Nussbaum, 1989).

When local anaesthetic agents are administered by the epidural route, they affect both motor and sensory nerves, and motor dysfunction, resulting in severe ataxia and recumbency, is a particular disadvantage for surgery when it is desirable that the animal should remain standing. Ataxia and recumbency may occur also following epidural administration of alpha ${ }_{2}$ agonists, especially at higher doses, either

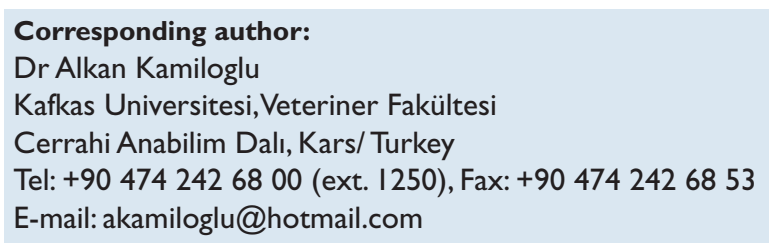

E-mail:akamiloglu@hotmail.com

due to systemic absorption of the drug and/or to local action on motor nerves (Skarda, 199I; Zaugg and Nussbaum, 1990). However, at appropriate doses, xylazine has been reported to be a suitable agent for providing analgesia without excessive ataxia and recumbency (Ko et al., 1989, Skarda et al., 1990; Zaugg and Nussbaum, 1990; Caron and LeBlanc, 1989; Lee et al., 2003). Upper caudal epidural administration of lidocaine and xylazine combination in cattle provides satisfactory analgesia for some surgical interventions such as fetotomy, repair of recto-vaginal fistulae, replacement of prolapsed uterus, vagina or rectum, facilitiation of embryo transfer, and perineal urethrostomy. Furthermore, this combination has a longer analgesic effect than xylazine used alone and should allow an animal to remain standing (Gündüz et al., 1992; Ko et al., 1989; Mpanduji et al., 1999).

The aim of the present study was to reveal whether epidural administration of xylazine and lidocaine combined with xylazine sedation could provide satisfactory analgesia for some surgical interventions carried out on the lower urinary tract, and on the umbilical and perineal regions.

\section{Material and methods}

The calves (Table I) exhibited various surgical disorders: urolithiasis $(n: 2)$, rectovaginal fistula $(n: 1)$, atresia ani $(n: 2)$, omphalophlebitis $(n: 2)$, omphaloarteritis (n:I) and umbilical hernia (n:2). 
TABLE I:Age, breed, sex, body weight, site of the epidural injection and surgical procedure for each of the 10 animals

$\begin{array}{ccccccc}\text { Case No } & \text { Breed } & \text { Age } & \text { Sex } & \text { Body temperature } & \text { Epidural injection } & \text { Surgical procedures } \\ \text { I } & \text { Zavot } & \text { I m } & \text { MC } & 45 & \mathrm{~L}_{6}-\mathrm{S}_{1} & \mathrm{HU} \\ 2 & \text { S.Angus } & \text { I5 } & \text { FC } & 40 & \mathrm{~L}_{6}-\mathrm{S}_{1} & \text { Omphalophlebitis } \\ 3 & \text { Simmental } & 25 \mathrm{~d} & \mathrm{FC} & 50 & \mathrm{~S}_{5}-\mathrm{Co}_{1} & \mathrm{R}-\mathrm{V} \text { fistula } \\ 4 & \text { Zavot } & 4 \mathrm{~m} & \mathrm{MC} & 55 & \mathrm{~S}_{5}-\mathrm{Co}_{1} & \text { Urolithiasis } \\ 5 & \text { S.Angus } & 15 \mathrm{~d} & \mathrm{FC} & 40 & \mathrm{~L}_{6}-\mathrm{S}_{1} & \mathrm{HU} \\ 6 & \text { EARed } & 20 \mathrm{~d} & \mathrm{FC} & 30 & \mathrm{~L}_{6}-\mathrm{S}_{1} & \text { Omphaloarteritis } \\ 7 & \text { Zavot } & 2 \mathrm{~m} & \mathrm{MC} & 50 & \mathrm{~S}_{5}-\mathrm{Co}_{1} & \text { Urolithiasis } \\ 8 & \text { S.Angus } & 2 \mathrm{~d} & \mathrm{FC} & 45 & \mathrm{Co}_{1}-\mathrm{Co}_{2} & \text { Atresia ani } \\ 9 & \text { Simmental } & \mathrm{Id} & \mathrm{dC} & 60 & \mathrm{Co}_{1}-\mathrm{Co}_{2} & \text { Atresia ani } \\ 10 & \text { S.Angus } & 3 \mathrm{~m} & \mathrm{MC} & 65 & \mathrm{~L}_{6}-\mathrm{S}_{1} & \text { Omphalophlebitis }\end{array}$

EARed: Eastern Anatolian Red; FC: female calf; S.Angus: Sweet Angus; MC: male calves; Co: coccygeal; S: sacral; HU: umbilical hernia; R-V fistula: recto-vaginal fistula; d: day; m: month.

The older calves were starved for 12 hours prior to operation. After surgical preparation of the sites for the epidural injections and the operation areas, each calf was given $0.05 \mathrm{mg} / \mathrm{kg}$ body weight of xylazine intramuscularly for sedation and then the combination of anaesthetic drugs $(0.2 \mathrm{mg} / \mathrm{kg}$ lidocaine $+0.02 \mathrm{mg} / \mathrm{kg}$ xylazine $+5 \mathrm{ml} 0.09 \% \mathrm{NaCl})$ was injected into one of the following epidural spaces: lumbosacral $\left(\mathrm{L}_{6}-\mathrm{S}_{1} ; \mathrm{n}: 5\right)$, sacrococcygeal $\left(\mathrm{S}_{5}-\mathrm{Co}_{1} ; \mathrm{n}: 3\right)$ or intercoccygeal $\left(\mathrm{Co}_{1}-\mathrm{Co}_{2}\right.$; $\mathrm{n}: 2)$.

Heart rate, respiratory rate and body temperature were recorded for each animal before the administration of the drugs and at 5, 10, I5,30 and 60 minutes afterwards. Responses to needle prick in the perineal and hindlimb areas and the umbilical region were assessed to monitor the effectiveness of analgesia and were graded as follows:

I: Normal reaction to pain sensation

2: Mild tail reflex and pain by needle prick

3: Tail reflex absent, mild response to needle prick

4: Tail and needle prick reflexes absent, good analgesia for surgery. These tests were repeated at I, 3, 5, 10, 15, 30, 60, 90, I20, I50 and 180 minutes after the epidural injection.
Statistical analysis

Measurements were compared with baseline values (time:0) by performing Anova followed by Tukey Test using Minitab statistical program (Minitab, 1998). Values were given as mean \pm standard deviation. Statistical difference was considered significant at $p<0.05$.

\section{Results and discussion}

Sedation with xylazine and epidural administration of the xylazinelidocaine combination resulted in a significant decrease of respiratory rate at 10,15 and 60 minutes $(p<0.01)$ and of body temperature at 60 minutes $(p<0.05)$; heart rate was decreased but the reduction was not statistically significant (Table 2).

Analgesia started at 3 minutes in the perineal region and at 15 minutes in the umbilical region following epidural injection. Perineal analgesia continued up to I 50 minutes (Figure I; Table 3).

However, adequate analgesia for the surgery was not achieved at the cranial side of the umbilicus and, therefore, surgical interventions in this region were performed with local infiltration anaesthesia. Intervals

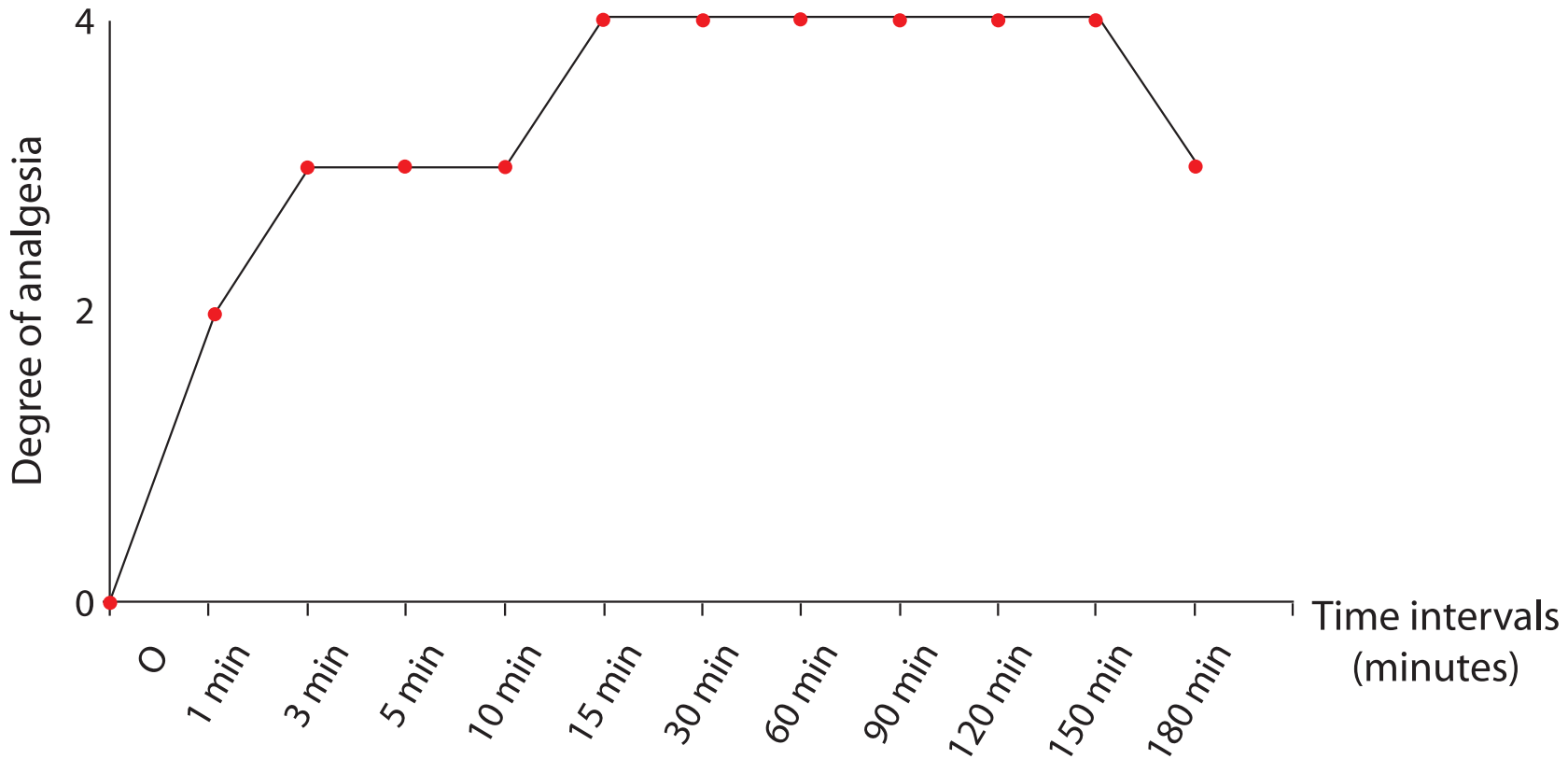

FIGURE I:Appropriate time intervals for surgical internevtion after administration of anaesthetic drugs. 
TABLE 2:Alterations in body temperature and heart-respiratory rates (mean $\pm S D$ ) in 10 calves at $0,5,10,15,30$ and 60 minutes after sedation with xylazine and epidural administration of xylazine and lidocaine combination

Time intervals (minutes)

$\begin{array}{lcccccc}\text { Parameters } & \mathbf{0} & \mathbf{5} & \mathbf{1 0} & \mathbf{1 5} & \mathbf{3 0} & \mathbf{6 0} \\ \text { Respiratory rate } & 27.00 \pm 4.14 & 25.00 \pm 4.45 & 20.40 \pm 3.86^{*} & 20.40 \pm 4.30^{*} & 23.40 \pm 4.90 & 21.20 \pm 4.23^{*} \\ \text { Heart rate } & 98.40 \pm 14.5 \mathrm{I} & 93.80 \pm 13.4 \mathrm{I} & 91.10 \pm 7.8 \mathrm{I} & 86.80 \pm 13.74 & 85.20 \pm 11.32 & 91.50 \pm 11.60 \\ \text { Body temperature } & 38.72 \pm 0.40 & 38.53 \pm 0.28 & 38.24 \pm 0.38 & 38.21 \pm 0.34 & 38.28 \pm 0.58 & 38.15 \pm 0.4 I^{* *}\end{array}$

$n: 10,{ }^{*}: p<0,01,{ }^{* * *}: p<0,05$

during which analgesia was sufficient for surgery are shown in Figure $\mathbf{I}$.

In order to avoid complications resulting from general anaesthesia, epidural injection of local anaesthetic agents has been widely reported for surgical interventions in the perineal region in cattle, horses, goats and sheep (Ko et al., 1989; Gündüz et al., 1992; LeBlanc et al., 1988; Trim, 1989). Investigation revealed that epidural administration of local anaesthetic drugs when used alone had various side effects and, although providing satisfactory analgesia for laparotomy, it did not always prevent response to visceral manipulation (Gündüz et al., 1992; Lewis et al., 1999; Trim, 1989). On the other hand, epidural injection of xylazine resulted in adequate analgesia, albeit with a slower onset than was achieved by the administration of local anaesthetic drugs; however, bradycardia, respiratory depression and hypothermia have been reported (Aminkov and Hubenov, 1995; Caron and LeBlanc, 1989; Grubb et al., 1993; Lewis et al., 1999). In the present study, the side effects of local anaesthetic/xylazine combination were minimized, and analgesia was prolonged by the low dosage of xylazine used for sedation and regional analgesia.

The results of the present study indicated that epidural administration of xylazine-lidocaine combination following sedation with xylazine provided satisfactory analgesia for perineal and lower urinary tract surgery without any complications. However, as observed by Lewis et al. (1999), satisfactory analgesia for umbilical surgery was not achieved.

\section{References}

Aminkov, B.Y. and Hubenov, H.D. (1995). The effect of xylazine epidural anaesthesia on blood gas and acid-base parameters in rams.
British Veterinary Journal I 5 I: 579-585.

Caron, J.P. and LeBlanc, P.H. (1989). Caudal epidural analgesia in cattle using xylazine. Canadian Journal of Veterinary Research 53: 486489.

DeRossi, R., Junqueira, A.L. and Beretta, M.P. (2003). Analgesic and systemic effects of ketamine, xylazine and lidocaine after subarachnoid administration in goats. American Journal of Veterinary Research 64: 5I-56.

Grubb, T.L., Riebold, T.W. and Huber, M.J. (1992). Comparison of lidocaine, xylazine, and xylazine/lidocaine for caudal epidural analgesia in horses. Journal of the American Veterinary Medical Association 20 I: II87-1190.

Grubb, T.L, Riebold, T.W. and Huber, M.J. (1993). Evaluation of lidocaine, xylazine and a combination of lidocaine and xylazine for epidural analgesia in llamas. Journal of the American Veterinary Medical Association 203: | $44 \mid$ - 1444.

Gündüz, S., Özaydın, í. and Çokal, A. (1992). Sıgırlarda xylazine ile epidural anestezi üzerine klinik çalısmalar. 3.Ulusal Veteriner Cerrahi Kongresi. I82-191.25-27 Haziran, Istanbul.

Ko, J.C.H., Althouse, G.C., Hopkins, S.M., Jackson, L.L., Evans, L.E. and Smith, R.P. (1989). Effects of epidural administration of xylazine or lidocaine on bovine uterine motility and perineal analgesia. Theriogenology 32: 779-786.

LeBlanc, P.H., Caron, J. P., Patterson, J.S., Brown, M. and Matta, M.A. (1988). Epidural injection of xylazine for perineal analgesia in horses. Journal of the American Veterinary Medical Association 193: | 1405-1408.

Lee, I., Yamagishi, N., Oboshi, K. and Yamada, H. (2003). Antagonistic effects of intravenous or epidural atipamezole on

TABLE 3: Distribution of the 10 calves amongst the grades of analgesia at intervals following sedation with xylazine and epidural injection of the lidocaine and xylazine combination

\begin{tabular}{cccccccccccccc} 
& \multicolumn{10}{c}{ Number of calves } \\
$\begin{array}{ccccccccccccccc}\text { Degree of } \\
\text { analgesia }\end{array}$ & interval (in minutes) & 0 & 1 & 3 & 5 & 10 & 15 & 30 & 60 & 90 & 120 & 150 & 180 \\
1 & 10 & 4 & 2 & 0 & 0 & 0 & 0 & 0 & 0 & 0 & 0 & 7 \\
2 & 0 & 6 & 7 & 3 & 2 & 1 & 0 & 0 & 0 & 0 & 0 & 2 \\
3 & 0 & 0 & 1 & 7 & 8 & 2 & 2 & 1 & 0 & 0 & 8 & 1 \\
4 & 0 & 0 & 0 & 0 & 0 & 7 & 8 & 9 & 10 & 10 & 2 & 0
\end{tabular}

I: Normal pain sensation to needle prick 2: Mild tail reflex and pain to needle prick

3:Tail reflex absent, mild response to the needle prick 4:Tail and needle prick reflexes absent, good analgesia for surgery. 
xylazine-induced dorsolumbar epidural analgesia in cattle. Journal of Veterinary Science 166: 194-198.

Lewis, C.A., Constable, P.D., Huhn, J.C. and Morin, D.E. (1999). Sedation with xylazine and lumbosacral epidural administration of lidocaine and xylazine for umbilical surgery in calves. Journal of the American Veterinary Medical Association 2 1 4: 89-95.

Minitab (1998). Reference manual., Release 12.1 for Windows. Minitab Inc.

Mpanduji, D.G., Mgasa, M.N., Bittegeko, S. and Batamuzi, E.K. (1999). Comparison of xylazine and lidocaine effects for analgesia and cardiopulmonary functions follawing lumbosacral epidural injection in goats. Journal of Veterinary Medicine A46: 605-6II.

Picavet, M.-T., Gasthuys, F.M., Laevens, H.H. and Watts, S.A. (2004). Cardiopulmonary effects of combined xylazine-guaiphenesinketamine infusion and extradural (inter-coccygeal lidocaine) anaesthesia in calves. Veterinary Anaesthesia and Analgesia 3 I: I I- 19.

Skarda, R.T. (1991). Local anesthetics and local anesthetic techniques in horses. In: Equine Anesthesia: Monitoring and Emergency Therapy. First edition. Edited by W.W. Muir and J.A.E. Hubble. St. Louis: Mosby Year Book, pp 199-246.

Skarda, R.T., St. Jean, G. and Muir, W.W. (1990). Influence of tolazoline on caudal epidural administration of xylazine in cattle. American Journal of Veterinary Research 5 I: 556-560.

St. Jean, G., Skarda, R.T., Muir, W.W. and Hoffsis, G.F. (1990). Caudal epidural analgesia induced by xylazine administration in cows. American Journal of Veterinary Research 5 I: I232- 236.

Thurman, J.C., Lin, H.G. and Tranquilli, W.J. (1989). A comparison of yohimbine and talazoline as antagonists of xylazine sedation in calves. Veterinary Surgery 18: 170-171.

Trim, C.M. (1989). Epidural analgesia with $0.75 \%$ bupivacaine for laparotomy in goats. Journal of the American Veterinary Medical Association 194: 1292-1296.

Zaugg, J.L. and Nussbaum, M. (1990). Epidural injection of xylazine: a new option for surgical analgesia of the bovine abdomen and udder. Veterinary Medicine 85: 1043-1046. 